\title{
Turismo sustentável e gestão ambiental em meios de hospedagem: o caso da llha do Mel, Paraná
}

\author{
Sustainable tourism and environmental management in the lodging \\ sector: the case of Ilha do Mel, Paraná
}

\author{
Matias Poli Sperb \\ Rivanda Meira Teixeira ${ }^{2}$
}

\begin{abstract}
Resumo
Esta pesquisa volta-se para a gestão ambiental praticada por meios de hospedagem da Ilha do Mel, no litoral do estado do Paraná. O estudo parte do pressuposto de que agentes do setor privado que atuam nesta localidade reconhecem a importância da natureza como principal atrativo turístico e, na medida do possível, buscam explorá-la de forma sustentável. Mais especificamente, procurou-se identificar o perfil dos empreendedores e suas motivações para a criação do negócio, caracterizar as empresas hoteleiras e analisar as ações desenvolvidas por esses empreendedores com relação à gestão ambiental. Tratando-se de uma pesquisa exploratória, os dados foram coletados principalmente por meio de entrevistas semi-estruturadas com os proprietários. É possível concluir que não existe, na maioria dos empresários, a preocupação com a utilização sustentável dos recursos naturais e que as ações relacionadas com o uso desses recursos não são decorrentes de uma consciência ambiental coletiva.
\end{abstract}

Palavras-chave: turismo sustentável, gestão ambiental, meios de hospedagem

\section{Abstract}

This research presents the environmental management practiced by the lodging sector in Ilha do Mel, located in the coast of the State of Paraná. The study presupposes that agents of the private sector that act in this place perceive the importance of the nature as the main tourist attractiveness, and in so far as possible, they look for to explore it in a maintainable way. More specifically, it searched for to verify which are the actions that the proprietors of lodgings develop with relation to the environmental administration, as well as their perceptions about their role and responsibility with the environmental sustainability in the place. As it is an exploratory and descriptive study, the data were collected mainly trough semi-structured personal interviews with the proprietors. It can be concluded that it doesn't exist in most of the entrepreneurs, the concern with the maintainable use of the natural resources and that the actions related to the use of those resources are not due to an collective environmental conscience.

\footnotetext{
${ }^{1}$ Mestre em Administração pelo CEPPAD / UFPR. E-mail mapolis@ gmail.com. Endereço. Rua Rio Grande do Sul, 841, ap. 53, Bairro Água Verde, 80610-100. Curitiba, PR..

2 Doutora em Administração pela Cranfield University, Inglaterra (2006). Pós Doutorado em Pequenas Empresas Turísticas na Bournemouth University, Inglaterra e na Strathclyde University, Escócia (20002001). Em 2007 fez Pós Doutorado sobre Empreendedorismo na HEC-Montreal, Canadá.. Emailrivandateixeira@terra.com.br. Endereço: Av. Prefeito Lotário Meisser 3400, Jardim Botânico, 80210-170Curitiba-PR.
} 
Keywords: sustainable tourism, lodging sector, environmental administration

\section{Introdução}

Paralelamente ao crescimento da consciência ambiental, o turismo desenvolveu-se de uma forma bastante rápida, assim como os demais segmentos da economia, com a utilização intensiva dos recursos naturais, sem uma preocupação com a preservação desses atrativos que formavam a base de sustentação da atividade (DIAS, 2003, p. 51). Vale lembrar que o setor de turismo já foi considerado, na década de 1960, a "indústria sem chaminés" e uma esperança de desenvolvimento econômico para países pobres.

Dados da FIEP/SENAI (2008) demonstram que, no Brasil, o setor de turismo representa pouco mais de $7 \%$ do valor adicionado total da economia. Esse valor mostra que o turismo, como atividade econômica, é um setor de grande impacto econômico, pois a indústria brasileira participou com 29,3\% do valor agregado - VA bruto no ano de 2005 —, mas, individualmente, não existe uma indústria com participação próxima à do turismo. No estado do Paraná, o fluxo de turistas apresentou crescimento entre os anos de 2002 e 2006, apesar de, em 2006, o número total de turistas ter sido menor que o valor identificado no ano de 2005. A receita obtida pelo setor, no estado, apresentou crescimento no período, alcançando mais de 1,5 bilhão de dólares no ano de 2006.

Vale destacar que o crescimento do setor de turismo está associado à geração de empregos e de renda. $\mathrm{O}$ forte apelo do setor para o crescimento regional advém de sua intensidade no uso de mão-de-obra, ao contrário da tendência apresentada nas últimas décadas na indústria e na agricultura, que, por meio da utilização de novas tecnologias e modelos de gestão e organização, liberam mão-de-obra de seus processos produtivos (FIEP/SENAI).

No entanto sabe-se que essa atividade econômica, como as outras, dependendo de sua forma de atuação, pode degradar o meio ambiente. Segundo Dias (2003), um destino turístico pode ter um boom de procura de um momento para outro, mas também pode entrar em decadência com a mesma velocidade com que cresceu. Nesse aspecto, o turismo, mais que outra atividade, é bastante dependente do planejamento e do contínuo monitoramento do aspecto geográfico onde se desenvolve. Na percepção de Rushmann (2001), o meio ambiente é a base econômica da atividade turística e apresenta oportunidades e limitações. Para Wahab e Pigram (1997), pelo fato de um lugar ter sido escolhido como uma destinação para turistas irá inevitavelmente acarretar mudanças no ambiente natural. As características que atraíram os primeiros turistas podem perder sua atratividade pela intensificação do uso.

A massificação de um lugar turístico, assim, representaria um risco em potencial máximo para a degradação do ambiente natural e a ruína do próprio turismo. Nesse sentido, Krippendorf (1975 apud RODRIGUES, 2000) manifestou-se contrário ao grande afluxo de pessoas aos recursos, alegando que "o turismo destruirá o turismo". Hetzer (1965) argumentou que, depois de terem arruinado o seu próprio ambiente, as pessoas que querem dispor de um ambiente natural se aglomeram em outros locais para destruir o ambiente de outros, em suas frenéticas tentativas de escapar, nem que seja por um curto espaço de tempo, da pressão competitiva, da poluição, do crime e do trabalho alienante. Dias (2003) enfatiza que o impacto do turismo sobre o meio ambiente é inevitável, e o que se pretende 
é mantê-lo em limites aceitáveis, para que não provoque modificações ambientais irreversíveis e não prejudique o prazer de o visitante usufruir o lugar. Para Wahab e Pigram (1997) nem todas as mudanças geradas pelas atividades de turismo levam, necessariamente, à degradação. Pelo contrário, se forem levadas a cabo de forma sensitiva, o desenvolvimento do turismo pode contribuir substancialmente para melhorar o ambiente e acarretar um aumento de prazer do turista e da sustentabilidade ecológica.

Levando em consideração esse contexto, a pesquisa volta-se para a gestão ambiental praticada por empreendimentos de hospedagem na Ilha do Mel, no estado do Paraná. O estudo parte do pressuposto de que agentes do setor privado, que atuam nessa localidade, percebem a importância da natureza como principal atrativo turístico e, na medida do possível, buscam explorá-la de forma sustentável. Mais especificamente, buscou-se identificar o perfil dos empreendedores e suas motivações para a criação do negócio, caracterizar as empresas hoteleiras e analisar as ações desenvolvidas por esses empreendedores com relação à gestão ambiental.

\section{A Ilha do Mel e o desenvolvimento do turismo}

A Ilha do Mel está situada no litoral norte do Paraná, entre Pontal do Paraná e a Ilha das Peças, subdividindo a barra da baía de Paranaguá em dois setores, representados pelos canais Norte e da Galheta. Ocupa uma área de $27,6 \mathrm{~km}^{2}$ da qual 2.710 hectares são de preservação ambiental, compostos por ecossistemas de restinga e de mata atlântica. Seu relevo é constituído por vasta planície de restinga ao norte e morros de altitude variável ligados por formações arenosas ao sul. Na década de 1990, paralelamente ao aumento de visitantes, na concepção de Esteves (2004, p. 209), o perfil dos turistas que freqüentavam a Ilha do Mel foi-se alterando para um tipo de "homo-urbano desenvolvimentista". Esse fato decorre da crescente busca, por parte de pessoas da cidade, por lugares com ambientes naturais e em bom estado de conservação. Também a mídia contribuiu para a divulgação da Ilha, a criação de infra-estrutura básica e daquela voltada ao turismo, como instalação do sistema de energia elétrica, a construção de pousadas, restaurantes, passarelas e trapiche, o funcionamento de linhas regulares de barco.

O turismo modificou radicalmente a paisagem e a sociedade da Ilha do Mel, tornando-se a sua principal atividade econômica. De pacata localidade de pescadores, no final da década de 1970, hoje se constitui em destacado ponto turístico do Paraná e do Brasil (ESTEVES, 2004). No entanto o crescimento turístico da localidade foi totalmente desordenado: “[...] por muito tempo houve a ausência de uma política de planejamento e gestão que fosse eficaz para lidar com a maneira caótica por que o turismo se vinha desenvolvendo na área" (SILVEIRA, 1998, p. 228). Por outro lado, na concepção de Kim (2004, p. 127), comparando a realidade aos objetivos das propostas e dos planos que guiaram a aplicação das políticas direcionadas à Ilha do Mel ao longo do tempo, vê-se "que sempre houve uma oscilação entre dois extremos: de um lado, a disposição em preservar a natureza, e, do outro, a vontade de favorecer o desenvolvimento do turismo de massa, falsamente anunciado como ecoturismo".

A atividade turística, com base no ponto de vista econômico, beneficiou principalmente o investidor de fora que domina a maior parte dos estabelecimentos comerciais (NETO, 1999). Os nativos, apesar de alguns se terem tornado proprietários de estabelecimentos 
comerciais, geralmente realizam os trabalhos pesados ou aqueles considerados menos nobres, como os carregadores e os coletores de lixo (ESTEVES, 2004, p. 76).

$\mathrm{Na}$ Ilha do Mel, existem vários problemas socioambientais, ocasionados pela grande demanda turística, destacando-se: "a destruição da flora e da fauna local, a depredação das praias, acúmulo de lixo, falta de água potável" (SILVEIRA, 1998, p. 228). O turismo, da forma como se implantou e consolidou na Ilha do Mel, além de ser apontado como um dos responsáveis pela degradação da qualidade de vida da população, acaba também afetando o bem-estar dos turistas que lá freqüentam (ESTEVES, 2004). Na concepção de Esteves (2004, p. 209), entre os problemas socioambientais, distinguem-se: a violência e o consumo de drogas; o emprego da mão-de-obra dos nativos em atividades consideradas menos nobres, como transporte de cargas, serviços gerais de limpeza e cozinha, coleta de lixo, etc.; a precariedade nas questões relativas à saúde e educação; a descaracterização da paisagem natural; a grande quantidade de lixo jogada e acumulada; a destruição da flora e da fauna; a degradação da qualidade da água.

\section{Gestão ambiental em meios de hospedagem}

Gonçalves (2004) argumenta que, desde os anos 1980 e 1990, a questão ambiental vem afetando diretamente uma variedade imensa de segmentos, como o de hospitalidade. Inicialmente, as preocupações estavam focadas nos segmentos industriais que causavam danos diretos ao meio ambiente, por meio das diversas formas de poluição. Atualmente, o problema é muito mais abrangente e está relacionado não apenas com o problema da poluição, gerado na saída do processo, mas também com a operação por completo. As atividades desse segmento são desenvolvidas por alguns pequenos estabelecimentos que consomem relativamente pouca energia, água, alimentos, papéis e outros tipos de recursos, representando uma pequena parcela de poluição em termos de fumaça, ruído e poluentes químicos. Contudo, argumenta Gonçalves (2004) que, se os impactos de todas essas pequenas empresas forem somados, se possa desenvolver um relativo potencial danoso ao meio ambiente. Junto a isso, consolida Molina (2001), a maioria dos estabelecimentos de hospedagem que utiliza algum mecanismo de gestão ambiental apresenta seus equipamentos periodicamente estragados ou em más condições, ou, mais simples ainda, fora de funcionamento por longos períodos.

Para De Conto (2005), os hotéis têm um papel ambiental importante e devem comprometer-se em desenvolver atitudes no sentido de utilizar significativas práticas ambientais em todos os processos; cumprir rigorosamente toda a legislação ambiental; minimizar o uso de energia, água e materiais; minimizar a geração de resíduos sólidos, reutilizando e reciclando; convidar os clientes, fornecedores e serviços terceirizados a participar de esforços para proteger o meio ambiente; fornecer a todos os funcionários o treinamento e os recursos requeridos para vir ao encontro dos objetivos traçados; comunicar abertamente sua política e as práticas ambientais para quem estiver interessado; e monitorar o impacto ambiental.

Alguns estudos foram desenvolvidos sobre a gestão ambiental do setor hospedagem pelo mundo. Por exemplo, Knowles et al. (1999) realizaram um levantamento sobre as iniciativas desenvolvidas a favor do meio ambiente pelo setor de hotelaria de Londres. Nesse estudo de caso, com 22 hotéis de médio e grande porte, esses autores verificaram alguns resultados bastante positivos: uma grande porcentagem dos respondentes $(94 \%)$ 
estava utilizando valores "verdes" de forma integrada com valores do negócio; três quartos responderam que sabiam onde encontrar informações sobre iniciativas ambientais; e um número significativo declarou ser membro de alguma instituição dedicada ao meio ambiente. Quanto aos pontos negativos, foi destacado que muitos respondentes não estavam seguindo uma agenda para melhorar o desempenho ambiental de seus negócios e muitos deles, mais de dois terços, não estavam realizando nenhuma ação favorável ao meio ambiente no período da pesquisa.

Outro estudo, no setor de hotelaria, abrangendo cadeias de hotéis e hotéis independentes de médio e grande porte, foi desenvolvido por Brown (1996) na Escócia. A autora buscou identificar se essas organizações mantinham, com relação ao meio-ambiente, uma atitude pró-ativa (por intermédio de uma política ambiental interna), ou reativa em resposta a, por exemplo, aumentos de custos de energia, pressões legislativas, pressões dos consumidores. Resultados da pesquisa demonstraram que, da amostra de 106 organizações, 43 possuem uma política ambiental. Verificou-se, ainda, que gerentes atuantes em organizações que apresentam uma política ambiental claramente definida sentiam-se claramente mais conscientes sobre o meio ambiente, em comparação àqueles atuantes em organizações que não a apresentavam. Junto a isso, comprovou-se também essa diferença em empregados, chefes de departamento e acionistas, na opinião dos próprios gerentes. A autora também constatou que os relatórios gerenciais mais utilizados são: controle de orçamento, manutenção da lucratividade e controle das reclamações dos clientes nas empresas de hotelaria. No entanto os resultados demonstraram que os gerentes de organizações "com políticas" estavam mais atentos aos resultados não-financeiros também, incluindo informação ambiental.

Os pesquisadores Tzschentke, Kirk e Lynch (2004) desenvolveram um estudo exploratório sobre as motivações para a tomada de decisão de desenvolver ações favoráveis ao meio ambiente e de pertencer a um esquema de certificação por parte de estabelecimentos de hospedagem de pequeno porte na Escócia. Para a coleta de dados, realizaram-se entrevistas pessoais em profundidade com membros da Green Tourism Business Scheme, uma instituição de certificação de empresas de turismo, e entrevistas com trinta proprietários de empresas de pequeno porte do setor de hospedagem na Escócia. Os resultados da pesquisa mostraram que essas organizações, por possuírem recursos limitados, tendem a responder mais às exigências legais do que a realizar práticas voluntárias, no que diz respeito ao meio ambiente. Contudo, quando as ações são desenvolvidas, a primeira motivação das empresas está voltada para a redução de custos pelo incremento de eficiência operacional com relação ao consumo de água, energia e disposição de resíduos.

Algumas pesquisas também já foram desenvolvidas no Brasil sobre gestão ambiental em meios de hospedagem. De Conto (2005), por exemplo, realizou uma pesquisa pela Universidade de Caxias do Sul, em que foi feito um estudo relacionado com a gestão de resíduos sólidos em meios de hospedagem, em 2001. O objetivo principal do projeto visou à elaboração de diretrizes para o gerenciamento de resíduos sólidos nesses meios. Para tal, diferentes atividades foram executadas: determinação da capacidade gravimétrica dos resíduos sólidos gerados no âmbito do Hotel da Universidade de Caxias do Sul, durante 12 meses; realização de entrevistas com gerentes e camareiras, em dez meios de hospedagem, sobre informações e condutas em relação ao manejo de resíduos sólidos e aplicação de questionários com hóspedes do Hotel Vila Verde da Universidade, relacionados com a percepção ambiental. 
Costa (2004) escreveu um livro sobre a experiência de sucesso do Hotel Bühler, no que diz respeito à atenção dada aos resíduos sólidos na região de Visconde de Mauá, Rio de Janeiro. Segundo a autora, esse hotel, no início de 2003, completava quase dois anos sem mandar um único saco de lixo para o caminhão de coleta da Prefeitura. Para isso, a experiência demonstra que, antes de qualquer coisa, é preciso criar novas rotinas; treinar funcionários; orientar os hóspedes; separar criteriosamente o lixo; organizar um depósito para recicláveis e lixo limpo; providenciar o destino e o transporte para os recicláveis; e dar uma aplicação aos resíduos que permanecem no hotel. Assim, a obra traz com detalhes a destinação dada a cada tipo de resíduo sólido gerado no estabelecimento.

\section{Metodologia}

Considerando os objetivos do presente estudo, elaboraram-se as seguintes perguntas de pesquisa: 1) Qual é o perfil dos empreendedores e das pousadas da Ilha do Mel? 2) Quais são as ações relacionadas com água, energia e resíduos desenvolvidas pelos empresários de pousadas com relação à preservação ou degradação do meio ambiente nesta ilha?

É importante destacar que esta pesquisa possui um caráter predominantemente qualitativo, no entanto se utilizará estatística descritiva para agrupar freqüências e padrões nos perfis das empresas, dos empresários e das suas ações de gestão ambiental, e perspectivas de preservação ambiental. Em função de seus objetivos, a pesquisa também pode ser classificada em exploratória e descritiva, quanto aos métodos utilizados. Apresenta, pois, um caráter exploratório, já que aborda um tema com pouco conhecimento acumulado e sistematizado. Pode-se considerá-la também como descritiva, tendo em vista que se busca conhecer um fato ou fenômeno sem precisar recorrer a relações causais entre suas variáveis. Dessa forma, na pesquisa, procura-se descrever um fato ou fenômeno com base em uma primeira aproximação, ou seja, em uma pesquisa exploratória.

Saliente-se que se realizou a pesquisa por meio da utilização do método documental, no que diz respeito aos dados secundários e, na coleta de dados primários, adotou-se a técnica de entrevista pessoal com a utilização de questionário, composto principalmente de perguntas abertas. As entrevistas pessoais foram feitas com os proprietários de pousadas na Ilha do Mel. Assim, foram ouvidos trinta proprietários de meios de hospedagem, o que corresponde a cerca de $30 \%$ do universo, que é composto de cem meios de hospedagem, segundo dados levantados por Esteves (2004).

\section{Análise dos dados}

Este estudo apresenta categorias de análise que reúnem elementos em agrupamentos sob títulos específicos. Tais agrupamentos são efetuados em razão de caracteres comuns entre os elementos presentes em cada agrupamento. Para o perfil dos empresários, consideraramse as categorias: idade; gênero; origem; escolaridade; experiência anterior; e motivação para iniciar o negócio. Para o perfil da empresa: tempo de funcionamento; número de empregados e de quartos. Com relação às ações referentes à gestão ambiental, apreciaramse as categorias: água de abastecimento; água residuária de emissões; energia e resíduos sólidos.

\subsection{Perfil dos empresários e suas motivações}


Cerca de $45 \%$ dos entrevistados estão na faixa de quarenta a cinqüenta anos de idade, $25 \%$, entre cinqüienta e sessenta anos, $20 \%$, entre trinta e quarenta anos e os extremos restantes (7\%) possuem menos de trinta e mais de sessenta anos de idade. Quanto ao gênero dos proprietários entrevistados, $57 \%$ são do sexo masculino e $43 \%$, do sexo feminino. Com relação ao local de origem, apenas $20 \%$ deles nasceram e se criaram na Ilha do Mel. Dos proprietários que têm como origem outras localidades (80\%), $60 \%$ deles são do próprio estado do Paraná, $10 \%$ de outros estados e $10 \%$ de outros países. A grande maioria dos proprietários entrevistados (87\%) reside na Ilha do Mel e apenas 13\%, fora dessa localidade. Da minoria, metade declarou passar seis meses do ano em Curitiba e o restante do tempo na Ilha; a outra metade possui gerentes que administram os negócios. Quanto ao grau de instrução dos proprietários, um pouco mais de $30 \%$ dos entrevistados possuem título de nível superior, e, em torno de um terço deles (10\%), possui pós-graduação. Cerca de $20 \%$ dos entrevistados completaram o ensino médio, e outros $20 \%$ declararam não ter nem o fundamental completo. Entre os $23 \%$ entrevistados restantes, $7 \%$ não completaram o ensino médio; $13 \%$, o fundamental; e 3\%, a graduação. No que diz respeito à experiência profissional anterior à gestão da pousada, a maioria dos proprietários que são oriundos da própria Ilha sustentava-se por meio da pesca e de outras atividades de extrativismo e/ou atividades de marinharia. Alguns proprietários (17\%) já tiveram outras microempresas, na maioria bares ou restaurantes. Outros $13 \%$ já foram funcionários de microempresas, como bares/restaurantes e mercearias. Alguns proprietários (10\%) já foram funcionários no setor de hospedagem. O restante dos proprietários já desenvolveu atividades em diversas áreas: advocacia, construção civil, ensino médio e superior, publicidade, artes, operação industrial, entre outras.

Com relação às principais motivações dos empreendedores para a criação das pousadas, verificou-se que quase metade (43\%) dos entrevistados decidiu ter uma pousada porque percebeu nesse tipo de negócio uma oportunidade de maiores rendimentos financeiros, por notar que o turismo estava consolidado ou aumentado na Ilha do Mel. Outros 37\% sentiram-se motivados pela beleza e pela tranqüilidade do local. Essa motivação transpareceu mais frequientemente nas entrevistas pelo termo "qualidade de vida" expresso pelos proprietários. Relacionadas com a qualidade de vida, citaram-se expressões como "um lugar sem violência nem roubo", "sem poluição do ar", "sem automóveis", "sem barulho", "com natureza abundante", "paz de espírito" e até mesmo como "um lugar propício para desenvolver atividades lúdicas e artísticas". Cerca de 13\% dos proprietários que não residem na Ilha transpareceram querer ter uma pousada mais como hobby, sonho concretizado ou facilidade de cuidado do que como negócio próspero, além de também se sentirem atraídos pela Ilha.

\subsection{Características dos meios de hospedagem}

Verificou-se que quase $90 \%$ das pousadas pesquisadas iniciaram suas operações a partir de 1990, podendo-se constatar que o desenvolvimento massivo do turismo na Ilha do Mel é relativamente recente. Com relação ao número de colaboradores, a maioria das pousadas chega a dobrar o número de empregados na alta temporada. No entanto, mesmo assim, não se refere a um número muito alto de colaboradores, dadas as dimensões dos negócios, pois a média de colaboradores contratados na alta temporada não é maior do que três. Por outro lado, também é relativamente alto o número de pousadas em que só trabalham os donos e seus familiares, principalmente na baixa temporada.

No que tange ao número de leitos por estabelecimento, observou-se uma grande variação: entre dez e noventa leitos. Entretanto mais que a metade das pousadas (60\%) possui um 
número relativamente baixo de leitos (de dez a trinta leitos). Por outro lado, os $40 \%$ restantes que possuem de trinta a noventa leitos apresentam cerca de $60 \%$ do total de leitos contabilizados nas trinta pousadas. $\mathrm{Na}$ totalidade, registraram-se 290 quartos, 281 banheiros e 960 leitos nas trinta pousadas da Ilha.

\subsection{Ações voltadas para a gestão ambiental dos meios de hospedagem}

\subsubsection{Com relação às fontes de água}

Verificou-se que a principal fonte de captação de água é a rede pública que é utilizada por mais de $80 \%$ das pousadas. Entretanto metade dos proprietários disse possuir poço próprio. Cerca de $60 \%$ dos proprietários também informaram comprar água mineral para beber, principalmente por causa da má qualidade de água da rede e dos poços próprios. Fontes pouco utilizadas pela maioria dos proprietários: água de bica e água da chuva, mesmo considerando que esta última exista em abundância na estação das chuvas. Entre os entrevistados, que utilizam em suas pousadas a combinação de água da rede com a de poço, $33 \%$ justificaram essa combinação, principalmente em razão de o abastecimento pela rede ser deficitário nos períodos em que a Ilha está com um grande número de turistas. Assim, utilizam o poço como uma fonte de emergência, caso venha a faltar água na rede pública.

Outra tática bastante utilizada, na resolução do problema de escassez de água, é a utilização de cisternas para o armazenamento. Dessa forma, quase a totalidade dos proprietários demonstrou grande insatisfação com a água da rede pública, não só pela falta nas épocas de maior necessidade, mas também pela contaminação e pelo custo, considerado elevado por muitos, se comparado à qualidade. Também se revelaram os entrevistados muito insatisfeitos com a condição da água dos poços, não só pela falta de pureza, mas também pelo custo da extração. Curiosamente, mesmo que a grande maioria dos proprietários tenha informado serem as águas, tanto da rede como dos poços, de má qualidade, ainda assim $20 \%$ dos proprietários disseram beber somente água dessas duas fontes.

Algumas práticas mencionadas com relação à economia do uso da água foram a sua reutilização e a utilização de equipamentos mais econômicos no uso da água, como lavadoras de louças. Porém a realização pelos empresários de práticas ambientalmente mais engajadas, considerando a realidade da água na Ilha do Mel, ainda são pífias. Ainda mais insensato: alguns deles, mesmo que minoria, não demonstraram a mínima preocupação em economizar água.

\subsubsection{Com relação ao tratamento das águas residuárias de emissões}

Cada pousada desenvolve o seu próprio tratamento, obedecendo à exigência mínima do IAP de utilização de fossa séptica, com base em uma estrutura com caixa de gordura, fossa e sumidouro, sem outras exigências específicas de dimensionamento, seleta de resíduos ou do material a ser utilizado. Segundo a maioria dos proprietários, não há uma preocupação maior do governo sobre a qualidade das fossas, seja por uma prévia exigência detalhada do projeto ou mesmo pela fiscalização na construção ou durante as operações da pousada. Observou-se também que, apesar de a maioria dos proprietários mencionar ter selecionado os diferentes resíduos em seus sistemas de esgoto, também se percebeu que esse procedimento era o mais simples possível e não seria suficiente para evitar que as fossas transbordassem e houvesse a contaminação de solo, mar, córregos e lençol freático. Esse, 
possivelmente, é um dos maiores problemas ambientais na Ilha e essa preocupação foi revelada por um dos entrevistados: "as fossas aqui na Ilha do Mel são precárias. Daqui a alguns anos vai piorar a qualidade da água do lençol freático. Todas as pessoas da Ilha dizem que a água tirada do poço hoje não é mais como era antes".

Outra preocupação relaciona-se a uma possível exaustão da água do lençol freático na Ilha pelo excesso de turistas ou, ainda, pela contaminação da água do mar no lençol, à medida que a água doce vai escasseando, uma vez que a camada de uma se sobrepõe à de outra. Um outro aspecto que merece destaque nessa discussão refere-se ao esgotamento das fossas e das caixas de gordura, pois, como não há serviço de retirada de resíduos na Ilha, eles são enterrados diretamente no solo dos quintais e áreas de reserva, quando as próprias fossas saturadas não são abandonadas.

\subsubsection{Com relação ao consumo de energia}

Verificou-se que todos utilizam energia elétrica da rede originada no continente, e apenas uma parcela pequena usa complementarmente tecnologias consideradas limpas, por exemplo, a energia solar - por meio de um projeto adotado pela COPEL de um chuveiro com painel para aquecimento solar. No entanto esse projeto governamental não foi levado adiante, pois o seu objetivo principal era o de suprir a carência de oferta de energia que, na época, era fornecida por um gerador operado pela queima de óleo diesel, localizado na própria Ilha. Constatou-se que esse tipo de equipamento, apesar de ter sido doado a integrantes da comunidade da Ilha, foi aceito com restrições pelos empresários, porque, segundo eles, os problemas decorrentes da utilização desses chuveiros são as dificuldades de manutenção, a falta de conhecimento sobre a sua utilização, os efeitos da salinização acelerando a deterioração e os entraves de utilização por um número maior de pessoas, haja vista que complementava apenas cerca de cinco a dez por cento do consumo de energia das pousadas. Um dos empresários explica os problemas que enfrentou utilizando esse chuveiro:

A gente tinha o chuveiro solar, mas a maresia corroía por dentro, saía uma água verde, acho que era da ferrugem. Não deu muito certo. Durou um ano esse chuveiro e, em uns seis meses, já começou a dar problema. Foi chamado o técnico, mas então viram que tinha salitre do mar e não tinha o que fazer. Depois levaram pro lixão. Não tinha manutenção também: só entregaram, instalaram e mais nada. Foi mal projetado. Acho que a maioria não utilizou muito tempo.

\subsubsection{Com relação à economia de energia}

A grande maioria dos entrevistados disse procurar fazê-la de diversas formas, tendo como motivação principal o custo. Cerca de $80 \%$ dos entrevistados disseram acompanhar os gastos na conta de luz e/ou no relógio medidor periodicamente. Quanto às ações específicas para economizar energia, 37\% informaram controlar o aquecimento dos chuveiros elétricos, os quais são grandes consumidores de energia nas pousadas. Para isso, os proprietários disseram trocar as resistências de 110 para 220, pois esquentam menos e, às vezes, também deixam a opção da temperatura da água em "morna" no chuveiro, em épocas de temperaturas mais elevadas. Alguns disseram que há variação de tensão na rede, principalmente na alta temporada, o que acaba causando a queima das resistências dos chuveiros. Além disso, também informaram ser a água da Ilha, por sua qualidade, em razão de detritos em suspensão e pouca pressão da rede de água, a grande causadora de 
problemas nos chuveiros, pois provocam o acúmulo de sujeiras nas resistências. Um dos entrevistados explica o processo:

Aqui na Ilha queima muito chuveiro, principalmente porque falta pressão e também porque tem oscilação de tensão. Mas o problema maior da queima do chuveiro é por causa dos resíduos da água, que [se] vão acumulando na resistência e aí ele aquece demais e estoura a resistência.

\subsubsection{Com relação aos resíduos sólidos gerados pelas pousadas}

Constatou-se que, apesar de muitos desses estabelecimentos realizarem uma seleção, mesmo que apenas bruta, entre os resíduos orgânicos e recicláveis, nem sempre dão uma destinação apropriada aos resíduos. Entre as pousadas que desenvolvem algum tipo de seleção mais cuidadosa dos resíduos sólidos, o incentivo para essa prática é o valor econômico dos materiais, como acontece com as latinhas de alumínio. Ou seja, o incentivo econômico é o principal motivador para o tratamento dos resíduos e não a preocupação ambiental.

\subsubsection{Com relação aos resíduos orgânicos}

Quase metade dos proprietários disse enterrar os resíduos. Questiona-se qual é o rigor na separação da matéria orgânica, pois foram encontrados, próximos de pousadas e residências, restos de lixo seco (tampas, sacos plásticos e outros pequenos resíduos recicláveis) que estão sendo enterrados ou despejados na mata e nas áreas de preservação. Apenas um dos empreendedores, entre todos os entrevistados, disse escolher as embalagens dos produtos que compra, ou seja, realiza uma triagem dos resíduos logo no início do processo de consumo, com as seguintes justificativas:

[...] nós não recebemos nenhum produto com embalagens que não tenha valor na reciclagem. Então, por exemplo, não compramos mais nenhuma bebida em garrafa. A garrafa produz uma dificuldade de transporte: é grande, é pesada, quebra e, quando fica estocada, cria água, cria mosquito da dengue. Então compramos só bebidas em lata. As latas são vendidas depois.

Verificou-se também que poucos entrevistados utilizam os resíduos orgânicos para a produção de compostagem. Esse tipo de processo propiciaria uma destinação ambientalmente recomendável, ao evitar que resíduos fossem enterrados em quantidade e jogados na mata indiscriminadamente, ou até mesmo que fossem levados pela coleta pública, visto que o destino final é um "lixão" a céu aberto no continente. Por outro lado, como a maioria dos terrenos é muito pequena, por determinação de loteamento mínimo estabelecido pelo IAP, é difícil a alocação de espaços nos quintais para esse fim.

\section{Conclusões}

Com relação ao perfil dos proprietários, verificou-se que a maioria deles não nasceu ou se criou na Ilha do Mel, mas residem nessa localidade. Esse dado leva a crer que os interesses dos proprietários, provavelmente, não giram apenas em torno do benefício econômico, mas também de outros benefícios ligados ao conceito de qualidade de vida do lugar em que residem, apesar de grande parte deles informar que a motivação foi criar um negócio pela atratividade econômica. Quanto às características dos empreendimentos, constatou-se que a grande maioria das pousadas pesquisadas teve as atividades iniciadas a partir de 1990, 
comprovando ser recente o desenvolvimento massivo do turismo na Ilha do Mel. Os empreendimentos são quase todos de pequeno porte e muitos deles não possuem funcionários e contam com mão-de-obra familiar. Contudo, durante a alta temporada, a maioria dos empreendimentos dobra o número de colaboradores, em decorrência do grande fluxo de turistas.

Ao analisarem-se as ações voltadas para a gestão ambiental nas empresas hoteleiras que participaram do estudo, pode-se concluir que, apesar dos problemas de abastecimento de água na Ilha do Mel, principalmente nos períodos de maior procura turística, há poucos artifícios para lidar com essa restrição nas pousadas. Exemplifica-se o baixo uso de água da chuva e da reutilização das águas, além da não-utilização de equipamentos mais eficientes no uso desse recurso pela maioria das pousadas.

No que diz respeito ao tratamento de efluentes, cada pousada desenvolve o seu próprio tratamento, obedecendo à exigência mínima do IAP de utilização de fossa séptica. Contudo, como não há uma ação mais rigorosa do governo nesse sentido, muitas fossas não apresentam dimensionamento suficiente para suportar o fluxo de turistas, além de outras negligências às especificações técnicas recomendáveis para evitar-se a contaminação do solo, dos riachos e do lençol freático.

O uso de fossas na Ilha do Mel, possivelmente, apresenta-se como um dos maiores problemas ambientais naquele sistema ecológico por causa da ação humana. Além da falta de critérios para a construção e a manutenção de fossas, o problema ainda se agrava mais quanto maior for a pousada e menores forem os cuidados com a economia de água. Apesar de tudo, esse problema só não é mais grave porque há falta de água durante os períodos de maior visitação turística. Entretanto o índice de pluviosidade é alto em algumas épocas do ano, principalmente no verão, o que acaba fazendo com que a contaminação das fossas se espalhe mais facilmente pela superfície da Ilha até chegar ao mar.

O fato de os proprietários não fazerem a captação de água da chuva apresenta-se também como algo positivo, no momento em que o consumo elevado de água acaba por aumentar o problema da contaminação do esgoto mal projetado e mal cuidado. Assim, caso venham a utilizar mais massivamente, na Ilha do Mel, os mecanismos de captação da água da chuva, no futuro, o problema de contaminação das fossas poderá ser potencializado.

Com relação ao uso de energia nas pousadas, em decorrência do custo ser relativamente alto e mais facilmente mensurável (se comparado a outros recursos relacionados com a gestão ambiental), observou-se maior controle do uso pelos proprietários de pousada, sendo o aspecto econômico o principal motivador.

Ao observar os resíduos sólidos gerados pelas pousadas na Ilha do Mel, constatou-se que muitos dos estabelecimentos comerciais fazem apenas uma seleção bruta dos resíduos, entre orgânicos e recicláveis, e que, muitas vezes, não dão uma destinação apropriada para eles. Entre as poucas pousadas que desenvolvem algum tipo de seleção mais cuidadosa dos resíduos sólidos, o incentivo para essa prática é o valor econômico dos materiais, a exemplo das latinhas de alumínio.

No que tange aos resíduos orgânicos, quase metade dos proprietários disse enterrá-los quando os "separam". Pode-se questionar o rigor na separação da matéria orgânica, pois foram encontrados, próximos a pousadas e residências, restos de lixo seco (tampas, sacos plásticos e outros resíduos recicláveis) e resíduos orgânicos, que estariam sendo 
enterrados, ou simplesmente despejados, na mata e nas áreas de preservação. Portanto se percebe que não há um comportamento orientado para a destinação dos resíduos orgânicos, e os entrevistados demonstraram não ter uma direção ou informação clara sobre o que fazer com esses resíduos.

Em suma, verificou-se que as ações desenvolvidas na gestão ambiental desses empreendimentos ocorrem, em geral, em decorrência do livre arbítrio dos proprietários, que adotam as práticas que lhes parecem mais convenientes no momento, motivados principalmente por aspectos econômicos, voltados para o curto prazo, sem maiores preocupações com a preservação ambiental da Ilha do Mel.

\section{Referências bibliográficas}

BROWN, M. Enviromental Policy in the Hotel Sector: "green strategy or stratagem?". International Journal of Contemporary Hospitality Management, p. 18-23, 1996.

COSTA, S. S. Lixo mínimo: uma proposta ecológica para hotelaria. Rio de Janeiro: Senac, 2004.

DE CONTO, S. Gerenciamento de resíduos sólidos em meios de hospedagem. In: TRIGO, L. G. G. (org). Análises regionais e globais do turismo brasileiro. São Paulo: Roca, 2005.

DIAS, R. Turismo sustentável e meio ambiente. São Paulo: Atlas, 2003.

ESTEVES, C. J. O. Turismo e qualidade da água na Ilha do Mel (litoral do Paraná). Curitiba, PR, 2004. Dissertação (Mestrado em Geografia) - Universidade Federal do Paraná.

FIEP/SENAI. Observatório de Prospecção e Difusão de Tecnologia - Estudo econômico do setor de turismo no estado do Paraná - 2008, Curitiba: Observatório Senai, 2008.

GONÇALVES, L. C. Gestão ambiental em meios de hospedagem. São Paulo: Aleph, 2004.

HETZER, N. D. Environment, tourism, culture. Disponível em: $<$ http://www.fieu.edu/ecosphere.shtml>. Acesso em: 25 abr. 2005.

KIM, K. M. Avaliação da sustentabilidade do modelo de desenvolvimento vigente na Ilha do Mel - PR. Pontal do Paraná, 2004. Monografia (Graduação em Ciências do Mar) Setor de Ciências da Terra, UFPR.

KNOWLES, T.; MCMILLAN, S.; PALMER, J.; GRABOWSKI, P.; HASHIMOTO, A. The development of environmental iniciatives in Tourism: responses from the London Hotel Sector. Internacional Journal of Tourism Research, 1, p. 255-65, 1999.

MOLINA, S. E. Turismo e ecologia. Bauru, SP: EDUSC, 2001.

NETO, R. F. As inter-relações da energia elétrica com aspectos de conforto e modernidade em pequenas comunidades. Um estudo de caso na Ilha do Mel - PR, Curitiba, 1999. Tese (Doutorado em Meio Ambiente e Desenvolvimento). Universidade Federal do Paraná.

RODRIGUES, A. B. Turismo e desenvolvimento local. São Paulo: Hucitec, 2000.

RUSHMANN, D. Turismo e planejamento sustentável: a proteção do meio ambiente. Campinas: Papirus, 2001. 
SILVEIRA, M. A. T. Ecoturismo na Ilha do Mel. In: LIMA, R. E. de; NEGRELLE, R. R. B (orgs). Meio ambiente e desenvolvimento no litoral do Paraná. Curitiba: Ed. da UFPR; Brasília: CNPQ, 1998.

TZSCHENTKE, N.; KIRK, D.; LYNCH, P. A. Reasons for going green in serviced accommodation establishments. International Journal of Contemporary Hospitality Management. vol. 16, n. ${ }^{\circ} 2$, p. 116-24, 2004.

WAHAB, S.; PIGRAM, J. J. Tourism, development and growth. London: Routledge, 1997. 